\title{
Context as a Basis for Understanding Pragmatic Ambiguity with Reference to Arabic
}

\author{
Dr. Misbah M. D. Al-Sulaimaan ${ }^{1}$, Lubna M. Khoshaba ${ }^{2}$ \\ ${ }^{1}$ Prof., Lebanese French University / Erbil \\ ${ }^{2}$ Asst. Lecturer, Lebanese French University / Erbil
}

\begin{abstract}
The study of ambiguity has been a central issue in the formulation of linguistic theory, and has been an area which serious psycholinguistic study has focused on since the past two decades.

The current study deals with "Context as a Basis for Understanding Pragmatic Ambiguity with Reference to Arabic" and the methods that can be used for translating this phenomenon into Arabic taking into consideration the same effect of the SL writer.
\end{abstract}

No doubt, pragmatic ambiguity is problematic since it is based on intentionality. However, it becomes more problematic when it is translated into Arabic, simply, because English and Arabic are genetically different languages.

This research paper aims at (1) studying the phenomenon of pragmatic ambiguity which is the output of any other type of ambiguity such as phonetic ambiguity, phonological ambiguity, lexical ambiguity, sentential ambiguity as well as semantic ambiguity, (2) making the context crystal clear which has an effective impact on understanding the expressions under investigation since intentionality cannot be deduced without knowing context, (3) specifying different patterns of pragmatic ambiguity in the books and articles of pragmatics, (4) translating the specified patterns into Arabic to show their realizations and whether, they will have the same effects as to that of source language ornot.

It is hypothesized in this research that (1) there is no formal correspondence between English and Arabic, (2) pragmatic ambiguity cannot be solved unless both context and cotext of the phenomenon in question are known, (3) all types of ambiguity cannot be interpreted unless the intention of the writer is clear which is context and cotext bound

To test the validity of the above mentioned hypothesis, it is to be noted that only eight different patterns have been chosen to be translated into Arabic, (2) these expressions were translated by six assistant lecturers in the department of Translation/Cihan University/Erbil, (3) Newmarks' method of communicative translation will be adopted in the research underinvestigation, since it tackles the intention of the writer.

The basic conclusions of this research are that, (1) all types of ambiguity are based on the intention of the writer, (2) there was no formal correspondence between both source language and target language, (3) the pragmatic ambiguity was solved by resorting to both cotext and context.

Keywords-Ambiguity, pragmatic, translation, context, cotext.

\section{INTRODUCTION}

Generally speaking, ambiguity is the quality or state of being ambiguous.It is a property of linguistic expressions. If an expression (word/phrase/sentence) has more than one interpretation, it can be considered ambiguous. Bach (1994) states that "a word, phrase, or sentence is ambiguous if it has more than one meaning.Leech(1987) defines ambiguity as " a one-many relation between syntax and sense".

Prakasam and Anvita(1993:94) state that ambiguity is the phenomenon of double or multiple signification. A word, phrase, or sentence is ambiguous if it has more than one meaning. In literary criticism ambiguity refers to the exploitation for artistic purposes of language which has multiple meanings. A phrase is vagueif and only if we do not know what is meant by it. If we do not know which of the two meanings is intended, then it is ambiguous to.

Ambiguity refers to the state of having or expressing more than one possible meaning or something open to more than one possible meaning. It refers to the state in which a word or a statement, any linguistic entity, can be understood in more than one way.

Conway (2002: 5) believes that ambiguity is uncertainty among specific alternatives. A word in a context can mean more than the isolated, and can also mean less than the isolated word, more because in context the word requires a new context and at the same time, less, because the word is delimited by that context. However, Grenat and Taher (2002: 10) point out that ambiguity means that utterances may differ semantically 
but not phonetically, i.e. they differ in their interpretation but not in their form.

Poesio and Artstein (1996:170) mention that natural language expressions can be ambiguous whether deliberately, as in poetry and humour, or unintentionally as in an ordinary language .Hurfard, et al (2007: 128) say that an utterance is ambiguous if it has two or more paraphrases which are not themselves paraphrases of each other.

To sum up, one can conclude that ambiguity is a linguistic phenomenon in which a linguistic expression can have more than one meaning or interpretation one of them is clear and the others are implied.

\section{TYPES OF AMBIGUITY}

The basic types of ambiguity can be summarized as follows:

2.1 Lexical Ambiguity: It occurs when a sentence contains a word or words that has or have more than one meaning.. This type of ambiguity is also known as "semantic ambiguity " .Lexical ambiguity arises when a word has more than one generally accepted meaning. It stems from the existence of homophony and polysemy. Homophony occurs when a single word has more than one meaning. For example, the word 'bank' can be used to denote either a place where monetary exchange and handling takes place or the land close to river, the bank of the river. ( For example, " Mary went to the bank", this sentence is ambiguous because the word 'bank' can either refer to building or to 'the edge of the river' ).

Schane (2000: 4) mentions that lexical ambiguity potentially occurswhenevera word has more than an objective or dictionary meaning. Ambiguity is potential because it is only in certain contexts that more than one of the meaningsmay be possible.

Al-Sulaimaan (2011: 2) defines "ambiguity as a linguistic phenomenonwhich refers to a word, a sentence, or any linguistic expression that has more than one meaning or interpretation. Ambiguity is of different types: phonetic, lexical, structural, cultural (among many others). Any linguistic expression with more than one interpretation is said to be multiply ambiguous as in the word "run" which has more than sixty meanings".

Lexical ambiguity is concerned with multiple interpretations of lexemes. A word is ambiguous if it involves two lexical items that have identical forms, but they are distinct, i.e. unrelated meanings.

2.2 Syntactic Ambiguity: It occurs when a phrase or a sentence has more than structure. For example, the sentence " They fed her dog biscuits", which means either a. They fed dog biscuits to her.

Or b. They fed biscuits to her dog..

Syntactic ambiguity arises not from the range of meanings of single words, but from the relationship between the words and clauses of a sentence, and the sentence structure underlying the word order therein. In other words, a sentence is syntactically ambiguous when a reader or listener can reasonably interpret one sentence as having more than one possible structure. Syntactic ambiguity is the presence of two or more possible meanings within a single sentence or sequence of words. Also called grammatical or structural ambiguity.

"Syntactic Ambiguity arises when a phrase can be parsed. Such phrases can be assigned to different interpretations because different grammatical structures can be assigned to the same string of words. "He ate the cookies on the couch", for example, could mean that he ate those cookies which were on the couch (as opposed to those that were on the table), or it could mean that he was sitting on the couch when he ate the cookies" (Thomas and Brommage,2007:1).

2.3 Pragmatic Ambiguity: Pragmatics is concerned with the study as communicated by a speaker (or writer) and interpreted by a listener (or reader). (i.e. pragmatics is the study of the speaker meaning. This type of the study involves the interpretation of what people mean in a particular context and how context influences what is said,(Yule:1996).

It can be found when people use expressions or utterances which have more than one rendering. This type of ambiguity can be represented by pragmatic concepts like indirect speech act, presupposition etc... Pragmatic ambiguity is here defined as ambiguity resulting from a particular communication which is intended by the speaker and/or hearer for a particular communicative purpose.

It refers to ambiguity in use, to a conversational situation where the ambiguity plays a role.It occurs when the speaker and the hearer disagree on what the situation is.

Berry, et al (2003:12) believe that "pragmatic ambiguity occurs when a sentence has several meanings in the context in which it isuttered. The context comprises the language context, i.e., the sentences uttered before and after cotext, and the context beyond language, i.e., the situation, the background knowledge, and expectations of the speakeror hearer and the writer or reader. This type of ambiguity results from the presence of deictic ambiguity".

Dastjerdi and Zamani (2009: 48) state that this type of ambiguity arises when the tone or the emphasis in an SL sentence is not clear. As an example:

(1) "I am working here today".

The emphasis of such a sentence can only be perceived, ifat all, from its context, although italics for one word would help. 
Pragmatic ambiguity arises when the statement is not specific, and the context does not provide the information needed to clarify the statement (Walton 1996).

Ted Gibson (2012) mentions that "Various people have said that ambiguity is a problem for communication. But once we understand that context disambiguates, then ambiguity is not a problem - it is something you can take advantage of, because you can reuse easy [words] in different contexts over and over again. Jejjud (2005) said that Pragmatic ambiguity occurs in the sociocultural and contextual conditions that affect the appropriate use of language in communication.

It is useful to place words as near as possible to the words they refer to.The clear use of past and present tense, the use of intonation and correct punctuation are useful to avoid ambiguity.

2.4 Semantic ambiguity: "Semantic ambiguity is a part of the specification of the grammar of a language; most, if not all sentences are semantically ambiguous, but their ambiguity need not to be noticed by the listeners, and in fact it is typically discovered only by linguistic research" (Poesio\& Artstein, 1996: 162).

For Baker, et al (2001: 17) "semantic ambiguity can arise when the meaning of a sentence could be determined only with the help of greater knowledge sources. Berry, et al (2003: 11) state that semantic ambiguity occurs when a sentence has more than one way of reading it within its contextalthough it contains no lexical or structural ambiguity. Semantic ambiguity can be viewed as ambiguity with respect to the logical form, usuallyexpressed in predicate logic, of a sentence.

Muhonen and Purtonen (2012: 2) regard that real semantic ambiguity occurs not only on the lexical level, but also on the syntactic level, where it leads to two different syntactic trees depending on the interpretation. So it can be concluded that semantic ambiguityis the case which cannot beeasily understood. It can be read with more than one way.

It has been mentioned above that the reason behind semantic ambiguity is coordination, scope, and referential ambiguity.

2.5 Cultural ambiguity: "Culture ... is that complex whole which includes knowledge, belief, art, morals, law, custom, and any other capabilities and habits acquired by man as a member of society. " (Cited in Avruch 1998:6)

"it is the set of attitudes, values, beliefs, and behaviors shared by a group of people, but different for each individual, communicated from one generation to the next.' (Matsumoto 1996: 16)
"Culture consists of patterns, explicit and implicit, of and for behaviour acquired and transmitted by symbols, constituting the distinctive achievements of human groups, including their embodiment in artifacts; the essential core of culture consists of traditional (i.e. historically derived and selected) ideas and especially their attached values; culture systems may, on the one hand, be considered as products of action, on the other, as conditional elements of future action." (Kroeber \& Kluckhohn 1952: 181.)

Bartoloni and Stevens (2010: 2) mention that cultural ambiguity goes through phases when it is stigmatized and when it receives approval. It often becomes most visible when a dominant, host culture protests against a real or imaginary 'contamination' by minoritycultures or when a culture that has been in subjection seeks to emancipate itself from cultural imperialism.

We can simply say that there are no two identical cultures, which would have the same values, history, systems, and social norms. Translators should be aware of and well acquainted with the culturalaspects of the original text.

\section{THEORIES OF AMBIGUITY}

Ambiguity draws the attention of the linguists in general and psycholinguists in particular. They are concerned with how ambiguity affects sentence processing. Psycholinguists believe that there are different theories to account for the mental process which listeners proceed in comprehending ambiguous sentences. Three notable theories to be discussed in this section are: (1) the garden path theory, (2) the many meaning theory, and (3) the mixed theory.

\subsection{The Many Meaning Theory}

"This theory claims that listeners compute two or more readings for each ambiguous construction and then immediately pick up one on the basis of context. For the above sentence, for example, the listeners would compute ' $a$ blow' and 'a drink' interpretations for the word 'punch'. They then pick the second since it matches with the context" (Clark and Clark, 1977: 81).

This theory seems also to be contradictive; since it cannot satisfy the question of how could listeners know a construction was ambiguous until they had computed at least two readings. A combination of both garden path and the many meanings theory has been suggested.

\section{CONTEXT OF SITUATION}

Widdowson (2000:126) defines "context" as "those aspects of the circumstance of actual language use which are taken as relevant to meaning." He further points out, "in other words, context is a schematic construct... the achievement of pragmatic meaning is a 
matter of matching up the linguistic elements of the code with the schematic elements of the context."

Cook (1999) in his definition, refers to the context as a form of knowledge the world and the term context can be used in a broad and narrow sense. In the narrow sense, it refers to (knowledge of) factors outside the text under consideration. In the broad sense, it refers to (knowledge of) these factors and to (knowledge of) other parts of the text under consideration, sometimes referred to as "cotext." (Cook:1999, 24).And "Context is the physical environment in which a word is used." (Yule:2000,128).

Although they are viewed from different perspectives for different purposes, these definitions have an important point in common: one main point of the context is the environment (circumstances or factors by some other scholars) in which a discourse occurs.

\section{REVIEW CONCLUSION}

In this section, it can be said thatambiguity characterizes as a pragmatic property. pragmatists argue over exactly what meaning is, but it surely involves associating expressions in a language withreality.Ambiguity can be resolved by providing context and providing cotext. Psychologists havementioned that there are several theories to account for the mental process which listeners proceed in comprehending ambiguous sentences:(1) the garden path theory, (2) the many meaning theory, and (3) the mixed theory.However, pragmatic ambiguity is based on three dimensions which are: (1) lexicons, (2) syntactic structure, and (3) context as well as cotext.

\section{WHAT IS TRANSLATION?}

Translation means replacing the source language elements by the target language elements. This means that lexicons, syntactic structures, semantic elements, pragmatic elements as well as cultural are replaced by the equivalent elements of the target language.

\subsection{Newmark's Types of Translation:}

Newmark (1988) proposed two types of translation. They are as follows:

\subsubsection{Semantic Translation.}

Semantic translation can be summarized as follows:

\footnotetext{
a. It is author-centred.

b. It pursues authors through process. Related to thought.

c. It is concerned with author as individual.

d. It is semantically and syntactically oriented.

e. It is faithful and more literal.

f. It is informative.

g. It is usually more awkward, more detailed, more complex, but briefer.
}

h. It is personal

6.1.2 Communicative Translation.

Communicative translation can be summarized as follows:

a. It is reader-centred.

b. It pursues authors intention process. Related to speech.

c. It adapts and makes the thought and cultural content of original more accessible to reader.

d. It is faithful and freer.

e. It is effective.

f. It is easily read, more natural, smoother, simpler, clearer, more direct, more conventional, confirming to particular.

g. It is social.

h. It is target language biased.

Regarding out paper, we will adopt communicative translation since it is after the intention of the writer and became pragmatic ambiguity is based on the intention of the writer which cannot be deduced unless both the cotex and context of situation are revealed.

\section{DATA ANALYSIS}

SL Text (1):

An old friend of mine teaches at that school.Kordoni (2008)

\section{Interpretation:}

Meaning 1:A friend of mine (whom) I have known for a long time teaches at that school. (friendship)

Meaning 2: A friend of mine who is old teaches at that school. (age)

$$
\text { not young }
$$

Regarding the example under discussion is lexically ambiguous because it has two different interpretations as it has been mentioned above. So, it is not clear whether the adjective " old" means old in his age or the friendship is old. Hence, pragmatic comes.

\section{TL Texts:}

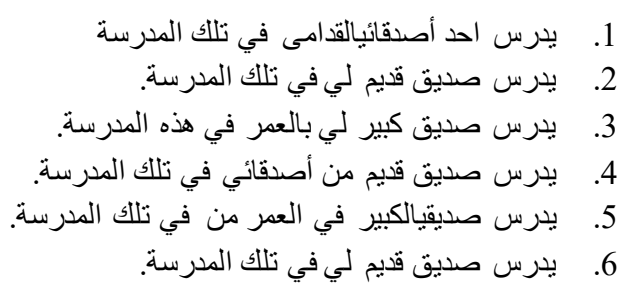

\section{Pragmatic Discussion:}

A close look at sentences $(1,2,4$, and 6$)$, reveals that they have the same meaning in the sense that this person has an old friendship who teaches at that school. As for the meaning of sentences ( 3 and 5), one can say that his friend is old in age. So, one cannot detemine the intentional meaning of this sentence unless it is used in a 
context. Hence, the problem of this sentence can be solved, for example, meaning (1) can be achieved as "An old friend of mine who teaches at that school, retired on pension" whereas meaning (2) can be stated as " An old friend of mine, from high school, teaches at that school.

\section{The Proposed Rendering:}

Considering the analysis above, one can say that the example in question can be given two renderings according to different contexts in order to remove the ambiguity . They are as follows:

$$
\text { 1. }
$$

\section{SL Text (2):}

Do you have the key ? Kordoni (2008)

\section{Interpretation:}

Meaning 1:Do you have the key of the room? (the main gate, etc.) (key)

Meaning 2:Do you have the key wordof that problem?(word)

With regard tothe examplein question, it is lexically ambiguous since it can be interpreted differently and the translators are unable to decide the exact meaning unless the sentence will be used in a good context. This means the interpretation is context bound.

\section{TL Texts:}

$$
\begin{aligned}
& \text { 1 . هل لديك مفتاح؟ } \\
& \text { 2. هل يوجد لديك حل للمشكلة؟ }
\end{aligned}
$$

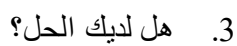

$$
\begin{aligned}
& \text { 4. هل لديك الحل ؟ لـ الحل؟ }
\end{aligned}
$$

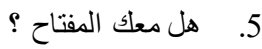

$$
\begin{aligned}
& \text { 6. هل لديك مفتاح الحل للمشكلة؟ ؟ }
\end{aligned}
$$

\section{Pragmatic Discussion:}

Looking at the sentences (1 and 5), one can deduce that they have the same meaning (i.e. asking about the key of the door or the main gate). Regarding the meaning of sentences (1, 2, 3, 4 and 6), it shows that question is about the solution for a problem. The problem of the ambiguity in meaning (1) which can be illustrated as " Do you have the key to open this door? And meaning (2) which is clear in this question "Do you have the key for this problem?".

\section{The Proposed Rendering:}

According to the analysis above, the example under investigation has two renderings so that the problem of ambiguity can be solved. This means that context should be apparent. They are as follows:

\section{SL Text (3):}

$$
\begin{aligned}
& \text { 1. هل لديك مفتاحالحل للمشكلة؟ } \\
& \text { 2. هل لديك المفتاح؟ لفناحل }
\end{aligned}
$$

I like ice-cream and cake. Kordoni (2008)

\section{Interpretation:}

Meaning 1: I like ice-cream and I like cake too.

Meaning 2: I like ice-cream together with cake.

In regard to the example under discussion, it can be consideredas a syntactic ambiguity since it has two different renderings, because of the conjunctive article "and" whether it refers to the ice-cream and cake separately or together. Hence, context should be made clear.

\section{TL Texts:}

\section{Pragmatic Discussion:}

$$
\begin{aligned}
& \text { 1. أحبالمثلجات و الكعك. } \\
& \text { 2. أحب أكل المثلجات مع الكعك. } \\
& \text { 3. أحب المثلجات و الكعلك. } \\
& \text { 4. يعجني أكل المثلجات و الكعك. } \\
& \text { 5. . أحب المثلجات مع الكعك. } \\
& \text { 6. أحب تنتاول المثلجات مع الكعك. }
\end{aligned}
$$

Looking at the translations above, one can say that sentences $(1$, 3and 4 ) have one intentional meaning which is having ice-cream with cake together, whereas sentences (2, 5 and 6) show another meaning in the sense that the speaker likes both ice-cream and cake separately. So, the ambiguity can be solved as " I like ice-cream and I like cake", while the ambiguity in meaning (2) can be resolved as "I like ice-cream and cake when they are mixed together".

\section{The Proposed Rendering:}

Two renderings can be given according to the analysis of different translations which are both context and cotext bound. They are as follows:

$$
\text { 1. }
$$

\section{SL Text (4):}

The lamb is too hot to eat.Kordoni (2008)

\section{Interpretation:}

Meaning 1:The living lamb is too hot to eat.

Meaning 2: The lamb meat is too hot to eat.

\section{TL Texts:}

$$
\begin{aligned}
& \text { 1. إن الخروف شديد الحرارة إذ يصعب أكله. } \\
& \text { 2. إن لحم الضان حار جدا لأكله بحيث لا نستطيع أكله. }
\end{aligned}
$$

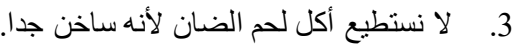

$$
\begin{aligned}
& \text { 4. . ل الاستطيع أكل لحم الحمل لحر ارته. }
\end{aligned}
$$

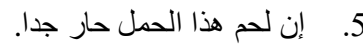

$$
\begin{aligned}
& \text { 6. ل ان نسنطيع تناول لحم الضان الآن لحرارته. }
\end{aligned}
$$

As for the example mentioned above, it is clear that it is lexically ambiguous, since the word " hot" has two meanings. This ambiguity can be clarified depending on the sentence's context. So, meaning(1) can be interpreted as "the lamb is too hot to eat now." , and meaning (2)can be achieved as " the meat of the lamb is 
too hot to eat". No doubt, what determines the meaning in this case is context.

Pragmatic Discussion:

An overall look at this sentence, it demonstrates that sentences (1,2 and 4) have one meaning which is that some people cannot eat lamb meat because of its heat while, sentences (3,4 and 5) show another meaning in the sense of that the lamb is too hot now and it cannot be eaten. This ambiguity can be solved by resorting to the context of situation as well as linguistic context (cotext).

\section{SL Text (5):}

The tank was full of water.Anjali \& Babn( 2014) Interpretation:

Meaning 1: The military tank was full of water. Meaning 2: The tank of waterwas full of water.

\section{TL Texts :}

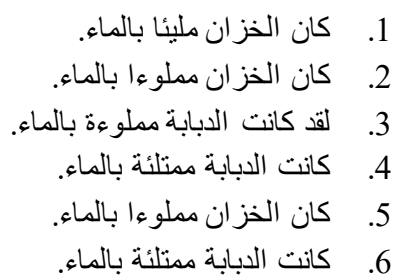

The type of ambiguity in this example is lexical because the word "tank" means either a military tank or tank of water. This type of ambiguity can be solved by the context of situation. So meaning (1) can be considered as "the tank was full water after the battle" and meaning (2) as "the tank the house of was full of water ". Determining which meaning is, one should specify the context of situation.

\section{Pragmatic Discussion:}

A close glance at sentences $(1,2$, and 5) reveals that they have one meaning which is that the tank used for water was full. Concerning the meaning of sentences (3, 4 and 6), they mean that the military tank was full of water.

\section{The Proposed Rendering:}

Considering the analysis above, the example in question can be given two renderings according to two contexts. These renderings are as follows:

\section{SL Text (6):}

$$
\text { 2. }
$$

Old men and women were taken to safe locations. Anjali \& Babn (2014)

Interpretation:

Meaning 1:Only men were old.

Meaning 2: Both men and women were old.

TL Texts:

$$
\text { 2. }
$$

$$
\text { 6 } 8 \text { 3. }
$$

In regard to this example, ambiguity in this example is syntactic since the adjective "old" can refer either to men only or to both men and women. So, the first meaning can be achieved in case we add " the women and only old men were taken to safe locations" the second meaning can be considered as "the men and women who are old were taken to safe locations". As a result, the extra meaning cannot be determined unless both the context of situation and cotext are known.

Pragmatic Discussion:

The previous translations show that the first sentence means the men only are old. So the adjective (old) belong to men, while the sentences 2-6 mean that both of men and women are old.

\section{The Proposed Rendering:}

According to the analysis, one can give two different renderings because the context of situation is different. They are as follows:

$$
\text { 2. }
$$

\section{SL Text (7):}

The man saw the girl with the telescope. Anjali \&

Babn(2014)

\section{Interpretation:}

Meaning 1:The man saw the girl carrying a telescope. Meaning 2:The man saw the girl through his telescope.

TL Texts:

$$
\begin{aligned}
& \text { 1. رأى الرجل الفتاة التي تحمل ناظور ا. }
\end{aligned}
$$

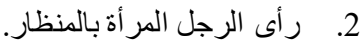

$$
\begin{aligned}
& \text { 3. رأى الرجل الفتاة بالمنظار. } \\
& \text { 4. ر رأى الرجل المر أة التي تحمل منظار ا. }
\end{aligned}
$$

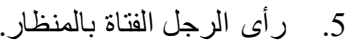

$$
\begin{aligned}
& \text { 6. رأى الرجل المر أة التي تحمل ناظور ا. }
\end{aligned}
$$

Concerning the example in question, it is of syntactic ambiguity whether the man saw a girl carrying a telescope, or he saw her through his telescope. The meaning is dependent on whether the preposition 'with' is attached to the girl or the man. This syntactic ambiguity depends on the intention of the writer (speaker). This intentionality cannot deduced until one knows the context of situation as well as the cotext. It is the context which says this meaning and not that.

\section{Pragmatic Discussion:}

A close look at the example under discussion, one can say that two interpretations can be given to above utterance which both are context bound: (1) the man saw the girl by using his telescope, and(2) the man saw the girl that was holding a telescope.

\section{The Proposed Renderings:}


Variation in meaning is based on different intentions of the writer. And these intentions cannot be deduced unless, the translator resorts to the context of situation. They are as follows:

$$
\text { 1. }
$$

\section{SL Text (8):}

Visiting relatives can be a bore.Kordoni (2008)

Interpretation:

Meaning 1:To visit relatives can be a bore.

Meaning 2: Relatives who visit us can be a bore.

TL Texts:

$$
\begin{aligned}
& \text { 1. إن زيارة الأقرباء مملة. } \\
& \text { 2. قد انكون مملة زيارة الأقارب. }
\end{aligned}
$$

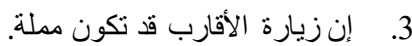

$$
\begin{aligned}
& \text { 4. إن الأقارب الذين نزور هم مملون. } \\
& \text { 5. إن الأقارب الذين نزوب الاين نزورهم مملون. } \\
& \text { 6. ق قد تكون زيارة الأقارب مملة. }
\end{aligned}
$$

As for the example mentioned above, it is semantically ambiguous. The word visiting can refer to the relative and the visit. So, meaning (1) is achieved if the context is known, for example, "visiting the relatives is a bore" and meaning (2) as "the relatives who visit us can be a bore". Hence, context of situation as well as cotext will solve the problem and decide which meaning.

Pragmatic Discussion:

A close glance at the previous translations demonstrates that sentences (1, 2, 3 and 6) have the meaning in sense of that the visiting is a bore, however the sentences (4 and 5) mean that the relatives who we visit are boring.

\section{The proposed rendering:}

Two renderings can be given according to the analysis above. The renderings are as follows:

$$
\text { 1. }
$$

\section{CONCLUSIONS}

1. ambiguity is the quality or state of being ambiguous.It is a property of linguistic expressions. If an expression(word/phrase/sentence) has more than one interpretation, it can be considered ambiguous

2. Most of the examples translated and analysed in the current paper, reveal that effective translations can be arrived out once the context is presnt. This means that removing ambiguity is context and cotext.

3. As for the method of translation, it has been found that two third of the data under investigation were translated communicatively, whereas one third was translated semantically.
4. Regarding the different types oftranslation, it is apparent that different syntactic structures were used by the translators (subjects of translation) which show the different realizations of the expressions in question.

5. No doubt, translation of pragmatic ambiguity which is based on intentionality is not easy to grasp unless both cotext and context are known.

6. One main important thing should be made clear is which is that all types of ambiguity, such as lexical, syntactic, semantic (among many other types) cannot be solved unless one should resort to the context of situation and cotext. And hence the problem of our study is solved.

\section{REFERENCES}

[1] Al-Sulaimaan, M. M. D. (2011): Semantics and Pragmatics, Mosul: Daar Ibn Al-Atheer for Publishing and Distribution.

[2] Anjali, M.K. \& Babn, Auto-P (2014): “Ambiguities in Natural Languages Processing"in International Journal of Innovative Research in Computer and communication Engineering, Vol.2, Special Issue 5.

[3] Avruch, K. (1998): Culture and Conflict Resolution, Washington DC: United States Institute of Peace Press.

[4] Bach, K. (1994): "Conversational Impliciture", Mind and Language, 9pp. 124-62.

[5] Baker, K. L., Franz, A. M. and Jordan, P. W. (2001): "Coping with Ambiguity in Knowledge-Based Natural Language Analysis". Center for Machine Translation and Department of Philosophy, Carnegie Mellon: CarnegieMellonUniversity Press.

[6] Bartoloni, P. and Stevens, A. (2010): "Introduction to Ambiguity in Culture and Literature".In: Comparative Literature and Culture, Vol.12, No.4, pp.1-6.

[7] Berry, D. M., Kamsties, E. and Krieger, M. M. (2003): "From Contract Draft to Software Specification: Linguistics Sources of Ambiguity". In: Journal of Systems and Softwares, Vol.28, No.2, pp.1-70.

[8] Clark, H. H. and Clark, E.V. (1977): Psychology and Language: AnIntroduction to Psycholinguistics, New York: Harcourt Brace Jovanovich, Inc.

[9] Conway, P. (2002): "Syntactic Ambiguity". In Law \& Justice Foundation of NSW, pp.1-45.

[10] Cook, G. (1999): Discourse and Literature, Shanghai: Shanghai Foreign, Language Education Press. 
[11] Dastjerdi, H. V. and Zamani, B. (2009): “A Semantic Study of The Translation of Homonymous Terms in Sacred Texts: The Qur'an in Focus". In: Journal of Language and Translation, Vol.10, No.1, pp.45-79.

[12] Grenat, M. H. and Taher, M. M. (2002): "On The Translation of Structural Ambiguity”. In: Satil Journal,Vol.23, No.12, pp.9-20.

[13] Hurfard, J. R., Hearsley, B. and Smith, M. B. (2007): Semantics,Cambridge: CambridgeUniversity Press ( $2^{\text {nd }}$ ed.).

[14] Jejjud, W. (2005): “Ambiguity". In College of Basic of Eduaction Researchers Education Journal, Vol.2, No.4,pp.223-235.

[15] Kordoni, V. (2008): Foundation of Languages Science and Technology (FLST) Lecture 4 hh://www.coli.uni-saarland.ed/courdes.

[16] Kroeber, A. Kluckhohn, C. (1952):Culture: A Critical Review of Concepts and Definitions, New York: Vintage Books.

[17] Leech,G.(1987): Semantics, Harmonds worth: Penguin Books.

[18] Matsumoto, D. (1996): Culture and Psychology, Pacific Grove, CA: Brooks/Cole.

[19] Muhonen, K. and Purtonen, T. (2012): "Detecting Semantic Ambiguity Alternative Readings in Treebanks".In: Linguistic Issues in Language and Technology, Vol.6, No.17, pp.1-11.

[20] Newmark, P. (1988): A Textbook of Translation, Oxford and New York: Pergamon.

[21] Prakasam,V. and Anvita Abbi(1993): Semantic Theories and Language Teaching, New Delhi: Allied Publishers

[22] Poesio, M. \& Artestein (1996): "Semantic Ambiguity and Perceived Ambiguity". In: Deemter, K. and Peters, S. (eds.) Semantic Ambiguity and Underspecification, Stanford, CA, pp.159-201.

[23] Schane, S. (2000): "Ambiguity and Misunderstanding in the Law". In: Words and Phrases, Harvard: Harvard University Press, pp.120.

[24] Thomas J. and Brommage, J. (2007): "Clarification and Linguistic Analysis". In: University of Tampa,pp.1-3.

[25] Walton, D. (1996): Fallacies Arising from Ambiguity, Dordrecht: Kluwer.

[26] Widdowson, H. (2000): Linguistics, Shanghai: Shanghai Foreign Language Education Press.

[27] Yule, G. (1996): Pragmatics, New York: Oxford University Press.

[28] Yule, G. (2000):Pragmatics, Shanghai: Shanghai Foreign Language, Education Press. 